\title{
A Construction Grammar Account of Left Dislocation in Persian
}

\author{
Yunes Azizian ${ }^{1}$
}

\author{
Arsalan Golfam² \\ Aliye Kord-e Zafaranlu Kambuziya ${ }^{3}$

\begin{abstract}
${ }^{1} \mathrm{PhD}$ candidate in Department of General Linguistics, Faculty of Humanities, Tarbiat Modares, Tehran, Iran ${ }^{*}$ Associate Professor in Department of General Linguistics, Faculty of Humanities, Tarbiat Modares, Tehran, Iran ${ }^{3}$ Associate Professor in Department of General Linguistics, Faculty of Humanities, Tarbiat Modares, Tehran, Iran ${ }^{*}$ Corresponding author: Arsalan Golfam, E-mail: golfamar@modares.ac.ir
\end{abstract}

\section{Doi:10.5901/mjss.2015.v6n6s2p98}

\section{Abstract}

Left dislocation (Id) is a very productive syntactic construction in persian, especially, in spoken language (dabir-moghaddam, 1992). Goldbergian construction grammar as a cognitive theory which gives the same weight to form and function is used, here, to analyze Id in persian. This theory by exploring some formal and functional elements such as argument structure, information structure and so on, could present a comprehensive analysis of the studied construction. The obtaining results showed that Idc, regardless of the words used in it, has its specific functions. It's a topic-promoting construction and its leftdislocated constituent, depending on the previous discourse, could be 'aboutness secondary topic' or 'contrastive focus' which is normally marked with postpositon '-ra'. Ld as an abstract construction is inherited by less abstract constructions and also inherits some properties from more abstract ones (or is motivated). Consequently, the theory could locate the position of Idc in the hierarchical network of constructions in the mind of persian speakers.

Keywords: Persian, Left Dislocation, construction grammar, argument structure, information structure, inheritance

\section{Introduction}

This study deals with Left Dislocation (LD) construction in Persian in the framework of Goldbergian construction grammar. LD is typically understood as a conversational syntactic construction that has some discourse functions which the premier of them in English is the introduction of referents that are somehow new to the discourse (Gregory and Michaelis, 2001). Main linguistic theories tend to include language in a container -a container of form or function. It seems that neither a mere formal nor a functional theory is able to provide a clear explanation for Persian linguistic data. On the other hand, each one of them could open up new horizons to researchers, ignoring any one of them, not only leads the researchers to a superficial and intuitive understanding of the linguistic phenomena, but also discrete their analysis from linguistic achievements and developments. Therefore, researchers must do selectively and utilize an efficient theory which considers, simultaneously, form and function along with historical changes and typological considerations (DabirMoghaddam, 2006: 263). Due to its importance, here we employ Goldbergian construction grammar which is, intrinsically, a cognitive linguistic theory and gives the same weight to form and function. In Goldberg's model, a complex word, phrase or sentence will count as a construction if some aspect of its form or meaning cannot be predicted from its subparts. A construction for Goldberg, like a Saussurean sign, is a form/function pairing and ranges in size from a single morpheme to 'partially lexically filled and fully general phrasal patterns' (Goldberg, 2006a: 5). Constructions in this model are in relation to each other through a network of relations and the value of one is determined based on its relationships to others.

The purpose of the present study is to analyze LD as a marked construction, in Persian, in the framework of the construction grammar. This goal will be achieved through providing a clear answer to these questions: 1) how can Persian LD process be analyzed from the perspective of Goldbergian construction grammar? 2) To which constructions in the mind of Persian native speakers is LD related? Based on these questions, hypotheses presented as follows: 1) Goldbergian construction grammar can provide a comprehensive explanation for LD in Persian and identify its formal and functional properties as a symbolic unit. 2) Also, it is able to locate the position of LD and its related constructions in the structured inventory of Persian constructions. 


\section{Literature Review}

Left Dislocation, probably first identified by Ross (1967), is superficially similar to preposing, but in LD a coreferential pronoun appears in the marked constituent's canonical position (Schiffrin et al, 2008: 131-132). LD is, as DabirMoghaddam (1992) claims, a very productive process in Persian, especially, in its spoken variety. It moves an item to the leftmost (sentence-initial position) and leaves a resumptive pronoun (or an anaphoric pronominal enclitic, according to Perry, 2005: 282) in its original place; exemplified by (1) below:

1) irædZi-0 $\varnothing_{\mathrm{j}}$ pul be-he $\Sigma_{\mathrm{i}}$ be-d-ej

Iraj-OM you money to-3S.PE1 IMP-give-3S

Iraji, give himi money.' (Mahootian and Gebhardt, 1997: 124)

It seems that this process as a strategy for topicalization ${ }^{2}$ involves movement of the indirect object to the front of the sentence while it is replaced with a pronominal clitic in its original position (Ibid). Noun phrases are the only elements which can be preposed via LD to initial position. Adjectives, adverbials and verbs cannot undergo such a movement (Ibid: 125). Dabir-Moghaddam (1992) believes that as a result of LD process, the moved item is marked with '-ra'; except when LD applies to Ezafe-construction ${ }^{3}(E C)$ in the subject position. The whole nominal part of a PP may also move by LD (cf. Dabir-Moghaddam, 2006: 54-55 for a detailed discussion). He also claims that in sentences with complement clauses, subject, direct object, indirect or oblique object of the embedded clause may be left-dislocated and set as the beginning constituent of the main clause (Ibid: 54-55). He also notes that LD can move a relative construction which may appear in any syntactic position in Persian to the sentence-initial position. In this process the head NP of the relative construction must not be coreferential with the subject of the relative clause (cf. Ibid: 57). Rahimian (1995), in contrary with DabirMoghaddam (1992), believes that the topicalized element is not always presented with '-ra', and the presence of this marker after the topicalized constituent is entirely optional. Shahidi (2000) examines topic-promoting strategies in Persian in the two functional frameworks; Systemic Functional Grammar and Givon's 1984. She counts scrambling as a topicpromoting strategy which topicalizes an element which represents without '-ra'.

In studies on LD in English, Prince's works are outstanding. She clearly identifies three form-function correlations for LD which are: a) 'Simplifying LD' which renders to facilitate the discourse processing of discourse-new entities, b) 'Poset LD' which triggers an inference on the part of the hearer that the left-dislocated element represents a salient entity, and c) 'Resumptive pronoun topicalization (island amnesty)' which is indeed topicalization in another pretense (cf. 1997: 121-133 for detailed discussion). Gregory and Michaelis (2001) claims that all the Prince's types of LDs have a common function; 'topic-promoting'.

\section{Theoretical Framework}

Adele Goldberg developed a type of construction grammar, especially in her 1995 prominent work ${ }^{4}$ that sought to extend the constructional approach from 'irregular' constructions such as words and idioms to 'regular' constructions. In order to do this, Goldberg focused on 'verb argument constructions'. In other words, she examined 'ordinary' sentences, like transitives and ditransitives, and built a construction grammar on the patterns she found there (Evans and Green, 2006: 667).

In the traditional view of semantics, meaning of a sentence is shaped through the accumulation of the meaning of individual lexical items (words and morphemes). In developing this idea, Construction Grammar recognizes a more comprehensive category called 'construction' as a bearer of meaning. Goldberg (1995: 4) asserts that " $\mathrm{C}$ is a CONSTRUCTION iff, $\mathrm{C}$ is a form-meaning pair $\left\langle\mathrm{F}^{5}, \mathrm{~S}^{6}\right\rangle$ such that some aspect of $\mathrm{F}$, or some aspect of $\mathrm{S}$, is not strictly predictable from C's component parts or from other previously established constructions". Both lexical and syntactic constructions are basically the same sort: both pair form with meaning (function) and they just differ in internal complexity (Ibid: 7). Even the most general syntactic constructions have corresponding general rules of semantic interpretation. Thus, constructions are fundamentally 'symbolic units' (Croft and Cruse, 2004: 257). Here, the symbolic unit as indicated,

\footnotetext{
${ }^{1}$ pronominal enclitic

2 Topicalization is a syntactic construction which moves a part of sentence to the sentence initial position. Such as: Beans, I don't like (Ross, 1967: 168).

${ }^{3}$ Its internal structure could be represented as [NP HN (head noun) -E NPM (modifier)].

4 'Constructions: A construction grammar approach to argument structure'

${ }^{5}$ stands for 'form'

${ }^{6}$ stands for 'semantic'
} 
is not just words, but can be morphemes, idioms, partially lexically filled and fully general linguistic patterns (Goldberg, 2003). In this approach, it is important to note the syntactic, semantic and pragmatic properties of the construction.

\subsection{Construction grammar assumptions}

As constructions blur the boundaries between lexicon and syntax, Goldberg assumes a 'lexicon-grammar continuum'construction. The main claim of her theory is that sentence-level constructions 'themselves carry meaning, independent of the words in the sentence' (Goldberg 1995: 1). Argument structure patterns contribute directly to the sentence meaning, and both the meaning of the construction and the meaning of the verb, together, will shape the overall meaning of the sentence. While the constructional meaning may be redundant with that of the main verb, the verb and construction may contribute distinct aspects of meaning to the overall interpretation. Lexical items commonly have a richer meaning than the abstract constructions (Bencini and Goldberg, 2000).

Goldberg (1995: 5) also assumes that knowledge of the language is represented as a 'highly structured lattice of interrelated information'. This view is in accordance with Langacker's 1987 viewpoint: "constructions form a structured inventory of speakers' knowledge of the conventions of their language" (63-76). Furthermore, Goldberg (1995: 5) rejects the idea of modularity of mind that knowledge of language is separate and distinct in nature from other kinds of knowledge. Instead, she believes that the properties of language directly reflect 'human experiences', 'conceptual organization' and 'construal'. Her model is monostratal and does not involve transformations. Accordingly, Goldbergian construction grammar is a cognitive approach to grammar (Evans and Green, 2006: 669).

\section{Discussion}

\subsection{LDC and argument structure}

In earlier theories of grammar it was thought that form and meaning of different patterns of sentence in a language were determined by the semantic and syntactic properties of the main verb of the sentence. Constructionists changed this belief and attribute this duty to the main verb of the sentence and its argument structure. Using a constructional approach to argument structure, the "differences in meaning between the same verb in different constructions are attributed directly to the particular constructions" (Goldberg, 1995:4). Verbs specify the participant roles that are obligatorily profiled and constructions specify which argument roles are profiled. In general, for a verb to occur in a particular construction, the participant roles associated with the verb must fuse with the argument roles associated with the construction (Ibid: 189).

$\mathrm{LDC}$, in Persian, can be structurally defined as [OBLi [SUBJ (OBL) RP $\left.7_{i} V\right]$ ]. This construction has two obligatory profiled argument roles which are an oblique ${ }^{8}$ which appears as the leftmost constituent, and a subject which may occur with verbs and other constructions which have a different number of profiled roles.

When verbs with different number of required arguments embed in sentences which inherit LDC, they must adapt their participant roles to argument roles of LDC.

\subsubsection{Monovalent verbs}

Monovalent or intransitive verbs in Persian such as '?amædæn' (to come) and 'ræfææn' (to go) which require one argument role to fulfill their meaning, must adapt themselves with valence needs of LDC and to do this will accept one more argument. Therefore, they must increase their valence by using a valence increasing strategy. Dixon and Aikhenvald (1997) believes increasing valence (valency is mentioned in original source) involves moving an argument from the periphery into the core. Applicatives and causatives are prototypical valence increasing devices (Ibid). In Persian, using an applicative (adding a PP as an oblique object) which is shown in (2) and the causative voice of intransitive verbs, as instantiated in (3), are two principle ways to add the number of arguments of a monovalent verb by one.

2) $g\left\{r_{\text {rmai }}-r_{0}, \varnothing_{j} ?\left\{z-\left\{\Sigma_{i}\right.\right.\right.$ moten $\left\{\right.$ fer- $\left\{m_{j}\right.$

heat-RA I of-PE hate-1S

As for the heat, I hate it.'

\footnotetext{
${ }^{7}$ Resumptive Pronoun

${ }^{8}$ In this study, we use the term Oblique as an umbrella term denoting all objects (direct, indirect, and prepositional) 
3) $p\left\{\right.$ nk $\left\{\right.$ i-ro, samanj ?otaq-o ba-ha $\Sigma_{\text {i }}$ xon $\left\{k--9 k æ r d-\varnothing_{j}\right.$ fan-RA Saman room-OM with-3S.PE cool made-3S 'As for the fan, Saman made the room cool with it.'

\subsubsection{Divalent verbs}

A divalent or transitive verb such as 'xord \{n' (to eat) has two obligatory arguments (subject and direct object). This kind of verb commonly can inherit LDC by preposing its oblique argument (direct object) as topic like (4). The resulted sentence, however is grammatical, but has a low frequency in spoken Persian.

4) ketabi-0, saman ${ }_{j}$ ? un $_{i}-0$ ferestad- $\varnothing_{j}$

book-RA Saman it-OM sent-3S

'The book, Saman sent it.'

Divalent verbs generally accept one more oblique in some ways to inherit LDC in the more productive way in Persian. One way is to add a PP as oblique and move its NP to the initial position of the sentence as in (5):

5) ?ostadi-0, $\varnothing_{j} ?\left\{z-\left\{\Sigma_{i} m\left\{\right.\right.\right.$ qal $\left\{-r o\right.$ gereft- $\left\{m_{j}\right.$

Professor-RA I from-3S.PE paper-OM took-1S

'As for the professor, I took the paper from him.'

Using a transitive verb in its causative voice is another way to match the roles of the verb and the construction. In this way, a participant (usually an oblique) will add, and can easily be preposed to the initial position of the sentence. Look at (6):

6) $\mathrm{b}\left\{\mathrm{t} \Sigma \mathrm{t} \Sigma\left\{\right.\right.$ i-ro, $\Sigma$ ejdaj $\mathrm{q}\left\{\mathrm{za}-\mathrm{ro}\right.$ be- $\Sigma$ i xor-un ${ }^{10}-\mathrm{d}-\varnothing_{\mathrm{j}}$

baby-RA Sheida food-OM to-PE eat-CC11-PAST-3S

'As for the baby, Sheida feed him/her the food.'

So, a transitive verb can change its valence requirements through one of the above ways and prepare itself to merge in LDC.

\subsubsection{Trivalent verbs}

Trivalent or ditransitive verbs obligatorily take two obliques (direct and indirect objects). Such verbs include the sense of 'dadæn' (to give). There are also some other verbs which can be used either transitively or ditransitively, such as 'ferestadæn' (to send), in this class of verbs the indirect object is optional (Mahootian and Gebhardt, 1997: 49). Ditransitive predicates, because of the number and the type of their arguments, can easily inherit LDC. A kind of ditransitive construction where the recipient receives a special coding is called 'indirect-object construction' (Haspelmath, 2008). In Persian, the indirect object of this type of constructions commonly represents as a dative oblique and receives preposition 'be' (to), for this reason, it also is called 'to-dative construction' (vaezi, 2015). When this construction inherits LDC its indirect object can be left-dislocated, as in (7):

7) $\operatorname{sabxun}\left\{\mathrm{i}-\mathrm{ro}, \varnothing_{\mathrm{j}}\right.$ kelid-a-ro be- $\Sigma_{\mathrm{i}}$ dad- $\left\{\mathrm{m}_{\mathrm{j}}\right.$

landlord-RA I key-PL-OM to-3S.PE gave-1S

'As for the landlord, I gave the keys to him'.

There is another kind of ditransitive construction in Persian which is called 'incorporated construction'. In this kind of construction the direct object loses its dependent grammatical markers (such as, object marker '-ra', indefinite marker 'je', plural marker, conjunct possessive pronoun and demonstrative) and incorporates to the main verb of the sentence, while, has no grammatical case (Dabir-Moghaddam, 2006: 174). It seems that there are two types of incorporated constructions in Persian which can be called 'dative incorporated construction' and 'object incorporated construction' which are shown in (8a) and (9a), respectively:

8) a. $\operatorname{mad}\left\{r_{i}\right.$ be $b\left\{t \Sigma t \Sigma e q\left\{z a--d a d-\varnothing_{i}\right.\right.$.

mother to baby (IDO'2) food ( $\left.\mathrm{DO}^{13}\right)+(\mathrm{V})$ give-3S

\footnotetext{
${ }^{9}$ A symbol for showing the boundary between two parts of a compound verb

10 It is the spoken form of Persian causative clitic and its written form is '-an'.

${ }^{11}$ Causative clitic

12 Indirect object

${ }^{13}$ Direct object
} 
'Mother gave food to the baby.' (Ibid)

9) a. $m\left\{r j\left\{m_{i} b\{t \Sigma t \Sigma\{-r o q\{z a--d a d-\varnothing\right.\right.$.

Maryam baby-OM food (DO)+ (V) give-3S

'Maryam gave food to the baby.' (Vaezi, 2015)

We can prepose the oblique object of (8a) via LD process or, in the words of this article; the dative incorporated construction (8a) can inherit LDC as is shown in (8b):

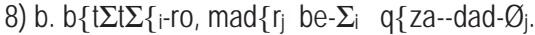

baby-RA mother to-PE food--gave-3S

'As for the baby, mother gave food to him/her.'

But when LD process applies on (9a) the resulted forms are unacceptable (9b) or of low frequency (9c) in spoken Persian:

9) b.*b $\left\{\mathrm{t} \Sigma \mathrm{t} \Sigma\left\{-\mathrm{ro}, \mathrm{m}\{\mathrm{r}\}\left\{\mathrm{m}_{\mathrm{i}} \mathrm{e} \Sigma \Sigma \quad \mathrm{q}\left\{\mathrm{za}--\mathrm{dad}-\emptyset_{\mathrm{i}}\right.\right.\right.\right.$.

baby-RA.OM Maryam-PE food (DO)+ (V) give-3S

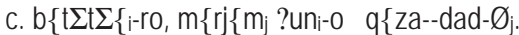

baby-RA Maryam-PE him/her-OM food (DO)+ (V) give-3S

In fact, after incorporating a trivalent verb such as 'dad\{n' (to give) to an object such as ' $q\{z a$ ' (food), as it seen in an 'object incorporated construction', which is shown in (9b), the verb's argument structure would change and decrease by one. Consequently, the resulted verb will be a divalent verb. Like transitive verbs it can inherit LD, as it more acceptable in spoken Persian, just when it accepts an oblique argument, such as (9d):

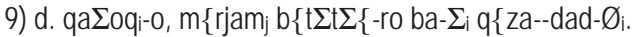

spoon-RA Maryam baby-OM with-PE food--gave-3S

'As for the spoon, Maryam feed the baby with it.'

As we saw in this subpart, a trivalent verb could embed in LDC and their roles merge with each other. In the case of 'object incorporated construction', it must receive an oblique object to inherit LDC.

\subsection{LDC and verb's participant roles}

An underlying semantic relation of a noun phrase with the main verb of a clause, have a number of labels in semantics, including: 'deep semantic cases' (Fillmore, 1968); 'thematic relations' (Jackendoff, 1972); 'participant roles' (Allan, 1986; 2014); 'semantic roles' (Givon, 1990), and 'thematic roles' (Jackendoff, 1990). The main participant roles are: agent, patient, theme, experiencer, beneficiary, instrument, location, goal, stimulus and source (Saeed, 2009: 153-154). There's sometimes overlap between some of these roles, for example, some linguists count theme and patient a same role (O'Grady, et al: 1997, 265-266). A participant role is used to express a role that a noun phrase plays in a proposition with respect to the action or state described by a sentence's verb (cf. Saeed, 2009: 153-154).

In Persian, participant roles which are related to oblique objects can be preposed to the sentence-initial position and the roles which are in relation with subject cannot be left-dislocated. Subjects, normally, in Persian tend to be agent and in some cases experiencer (commonly the subject of sense verbs such as 'did\{n' (to see), ' $\mathrm{\Sigma} \Sigma \Sigma \mathrm{E}$ id $\{\mathrm{n}$ ' (to taste), 'ehsas--k\{rd\{n' (to feel) and so on). When agent/experiencer is subject, it cannot also appear before itself; so, it cannot be the first constituent of LDC. The other participant roles can be left-dislocated freely and play the role of LDC's leftmost constituent. Instances of preposing the roles stimulus, instrument, patient, source, recipient, beneficiary, location and goal via LD process are, respectively, presented in (2), (3), (4), (5), (7), (10), (11) and (12):

10) [dust- $\{\mathrm{m}] \mathrm{i}-0, \varnothing_{\mathrm{j}}$ pul-o $\mathrm{b}\left\{\mathrm{ra}-\Sigma_{\mathrm{i}}\right.$ ferestad-ij?

friend-1S.PE-RA you money-OM for-3S.PE sent-2S.PE

'As for my friend, did you send the money to him?'

11) [park-e $m\left\{h\{l e]_{i}-r o, \varnothing_{j} \quad h\left\{r r u z d\left\{r-e \Sigma_{i} v\{r z e \Sigma\right.\right.\right.$ mi-kon-imj

Park-E neighborhood-RA we everyday in-3S.PE exercise DUR-do-1P

'As for the neighborhood park, we everyday exercise in it.'

12) polisi-0, $\Sigma$ ejdaj govahinam $\left\{-\Sigma-0\right.$ be- $\Sigma_{\text {i }}$ dad- $\varnothing_{j}$

policeman-RA Sheida licence-3S-OM to-PE.3S handed-3S

'As for the policeman, Sheida handed her license to him'

It must be noted that, in Persian, speakers commonly tend to prepose Patient to the sentence-initial position via topicalization, as in (13), rather than LD, as is presented in (4). Topicalization of patient is more productive than its left dislocation and gives a more acceptable linguistic form. 
13) ketab-0, samanj ferestad- $\varnothing_{j}$

book-OM.RA Saman sent-3S

'The book, Saman sent.'

\subsection{LDC and Aktionsart type}

Constructions, in addition to their ability to identify the type of participant roles, must also be able to specify the types of the verbs which can combine with them. In other words, according to Goldberg (1995: 49), "they must also specify the way in which the event type designated by the verb is integrated into the event type designated by the construction." Van Valin and LaPolla (1997) argue that verbs represent different 'states of affairs', which can be sorted as events, actions, processes, and situations. Accordingly, they propose four main sorts of verbs based on the 'Aktionsart ${ }^{14}$ ' distinctions which are states, achievements, accomplishments, and activities. States which often express situations are non-dynamic and unlimited to time as in 'danest $\{\mathrm{n}$ ' (to know), while activities which often express actions are dynamic and also temporally unbounded as in 'rah-- $\mathrm{r}\{\mathrm{ft}\{\mathrm{n}$ ' (to walk). Achievements which often express events are immediate changes and have an inherent end point as in 't $\{\Sigma x i s--d a d\{n$ ' (to realize). Accomplishments which often express processes are noninstantaneous changes that lead to an end-point as in ' $q\{$ rq-- $\Sigma 0 d\{n$ ' (to sink). These verbs sometimes play different roles with their causative forms; because of this dichotomy in treatment he proposes their causative forms also as distinct verb classes. In this way the number of verb types reached to 8 . Note to the occurrence of verbs belong to every Aktionsart type in Persian with LDC in the following instances:

14) State:

$\mathrm{s}\left\{\mathrm{gi}_{\mathrm{i}-0, \mathrm{~b}} \mathrm{~b}\left\{\mathrm{t} \Sigma \mathrm{t} \Sigma \mathrm{e}_{\mathrm{j}} ?\left\{\mathrm{z}-\left\{\Sigma_{\mathrm{i}} \mathrm{t}\left\{\mathrm{rsid}-\varnothing_{\mathrm{j}}\right.\right.\right.\right.\right.$

dog-RA baby of-PE scared-3S

'As for the dog, the baby scared of it.'

15) Causative state:

maski-0, $\varnothing_{j}$ ba-(ha) $\Sigma_{\mathrm{i}} \mathrm{b}\left\{\mathrm{t} \Sigma \mathrm{t} \mathrm{t} \Sigma\left\{-\mathrm{ro} \mathrm{t}\left\{\mathrm{rs}-\mathrm{un}-\mathrm{d}-\varnothing_{\mathrm{j}}\right.\right.\right.$

mask-RA he/she with-PE baby-OM frighten-CC--PAST-3S

'As for the mask, he/she frightened the baby with it.'

16) Activity:

?est $\left\{\mathrm{xr}_{\mathrm{i}-0}, \varnothing_{\mathrm{j}}\right.$ ta $? \mathrm{ax}\left\{\mathrm{r}-\mathrm{e}-\Sigma_{\mathrm{i}-\mathrm{O}} \quad \sum \mathrm{ena}-\mathrm{-k}\left\{\mathrm{rd}-\left\{\mathrm{m}_{\mathrm{j}}\right.\right.\right.$

pool-RA I to end-E-PE-OM swim--did-1S

'As for the pool, I swim to the end of it.'

17) Causative activity:

mejdani-0, goruhban ${ }_{j} \mathrm{~d}\left\{\mathrm{r}-\mathrm{e} \Sigma_{\mathrm{i}} \mathrm{s}\left\{\right.\right.$ rbaz-a-ro reZe--bord- $\varnothing_{j}$

field-RA sergeant in-PE soldier-P-OM march--took-3S

'As for the field, the sergeant marched the soldiers in it.'

18) Achievement:

gu $\Sigma \mathrm{i}_{\mathrm{i}-0,} \varnothing_{\mathrm{j}}$ ba-(ha) $\Sigma_{\mathrm{i}} \mathrm{m}\left\{\right.$ rizi-0 $\mathrm{t}\left\{\Sigma \mathrm{xis}-\mathrm{-dad}-\varnothing_{\mathrm{j}}\right.$

stethoscope-RA he/she with-PE disease-OM diagnose--gave-3S

'As for the stethoscope, he/she diagnosed the disease with it.'

19) Causative achievement:

$\mathrm{s}\left\{\right.$ ndZaqi-0, b $\left\{\mathrm{t} \Sigma \mathrm{t} \Sigma \mathrm{e}_{\mathrm{j}}\right.$ ba-(ha) $\Sigma_{\mathrm{i}}$ badkonak-o terek-un-d- $\varnothing_{\mathrm{j}}$

pin-RA kid with-PE balloon-OM pop-CC-PAST-3S

'As for the pin, the kid popped the balloon with it.'

20) Accomplishment:

$\mathrm{n}\left\{\mathrm{rm}\left\{\right.\right.$ fzari-0, $_{1} \varnothing_{\mathrm{j}}$ violon-o $\quad$ ba-(ha) $\Sigma_{\mathrm{i}}$ jad--gereft- $\left\{\mathrm{m}_{\mathrm{j}}\right.$

software-RA I violin-OM with-PE learn--took-1S

'As for the software, I learned the violin with it'

21) Causative accomplishment:

$n\left\{\right.$ rm $\left\{\right.$ fzari-0, $\varnothing_{\mathrm{j}}$ violon-o ba-(ha) $\Sigma_{\mathrm{i}}$ jad--mi-de- $\varnothing_{\mathrm{j}}$

${ }^{14}$ Aktionsart which also called 'lexical aspect' and 'aspectual class' is concerned with the temporal semantics of an utterance in terms of the time intervals conceptualized in the construal of the situation expressed by that utterance. The fundamental criterion is the inclusion or non-inclusion of starting points and/or end-points (boundaries) in the conceptualization of the situation (Sasse, 2006). 
software-RA he/she violin-OM with-PE teach--DUR-give-3S

'As for the software, he/she teaches the violin with it.'

Apart from the eight principle types of verb, in Van Valin's newer manuscripts $(2005,2013)$, he introduces semelfactives, Active Accomplishments and their causative forms as other types. semelfactives include punctual temporary events which don't lead to any result, as in '? $\{\mathrm{tse}-\mathrm{-k}\{\mathrm{rd}\{\mathrm{n}$ ' (to sneez) and Active Accomplishments include punctual dynamic events, as in ' $r\{n g--z\{d\{n$ ' (to paint). These four newer types also can happen with LDC. Consider the subsequent instances:

22) Semelfactive:

ma $\Sigma$ in $_{i}-0$, kjanaj be d $\left\{r-e-\Sigma_{\text {i }}\right.$ xord- $\varnothing_{j}$

car-RA Kiana to door-E-PE hit-3S

'As for the car, Kiana hit the door of it.'

23) Causative semelfactive:

ma $\Sigma$ in $_{i}-0$, kjanaj tup-o be $d\left\{r-e-\sum_{i} z\left\{d-\varnothing_{j}\right.\right.$

car-RA Kiana ball-OM to door-E-PE CAUSE TO hit-3S

'As for the car, Kiana hits the ball to the door of it.'

24) Active accomplishment:

q $\left\{\mathrm{lt}\left\{\mathrm{k}_{\mathrm{i}-0}, \varnothing_{\mathrm{j}}\right.\right.$ divar-e ?otaq-o ba- $\Sigma_{\mathrm{i}} \mathrm{r}\left\{\mathrm{ng}-\mathrm{-b}-\mathrm{z}\left\{\mathrm{n}-\varnothing_{\mathrm{j}}\right.\right.$

roller-RA you wall-E room-OM with-PE paint--IMP-hit-2S

'As for the roller, paint the wall of the room with it.'

25) Causative active accomplishment:

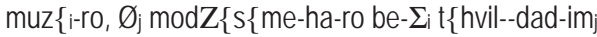

museum-RA we statue-PL-OM to-PE deliver--gave-1P

'As for the museum, we deliver the statues to it.'

As we see in the above examples (14-25), LDC in Persian contains all the aktionsart types and the construction imposes no restriction on using any type.

\subsection{LDC and Information Structure}

Analyzing the information structure of a construction is also of high importance in determining the functional and the formal properties of the construction as a symbolic unit. According to Lambrecht, information structure is the part of grammar that pairs conceptual predicates with syntactic structures in accordance with the mental states of the verbal communication participants who interpret these structures in the given discourse (1994: 6). Let begin to examine the information structure of LDC in Persian by considering the following example (26):

26) a. Øi ba pit $\Sigma g u \Sigma t i t \Sigma i k a r k\{r d-i$ ?

you with screwdriver what did-2S

'What did you do with the screwdriver?'

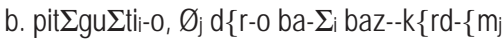

screwdriver-RA I door-OM with-PE open--did-1S

'As for the screwdriver, I opened the door with it.'

In the above mini-discourse, the speaker (26b) preposes 'pit $\Sigma g u \Sigma t i '$ (screwdriver) NP. The left-dislocated NP functions as the sentence 'topic'. It is topic, because, according to Lambrecht (Ibid: 131) it includes the concept of aboutness, and the proposition of the sentence expresses some information about it (pit $\Sigma g u \Sigma t i)$. Lambrecht believes that there are two kinds of topic: a constituent which is not primarily the topic of the sentence, and has been moved to the sentence initial position, he named it "secondary topic", and a constituent which is primarily the topic of the sentence, he called it "primary topic" (Ibid, 147). As Givón (1990: 901-908) believes, the primary topic is more important, continuous and recurrent than the secondary topic and tends to be encoded cross-linguistically as a subject, while the secondary topic tends to be encoded as an oblique (direct, indirect or prepositional) object (Croft 1991). The left-dislocated NP (pit $\Sigma g u \Sigma t i)$ is a secondary and not a primary topic, because it is not the underlying and canonical topic of the sentence, but is moved to the sentence-initial position via LD process. Since Persian is a pro-drop language, the primary topic of the sentence (26b) is the null subject ' $\varnothing$ ' (here is equal to 'l') which is recoverable in the sentence through a person suffix ($\{\mathrm{m})$ attached to the main verb (baz-- $\mathrm{k}\{\mathrm{rd}$, 'opened'). This suffix accomplishes the duty of agreement between the dropped subject and the verb of the sentence. The left-detached constituent as the 'aboutness secondary topic' of the sentence is marked with the postposition '-o' (an spoken form of '-ra'). Preposed NP contains 'old information' because is 
mentioned in the previous discourse (26a), therefore, this kind of topic following López (2009: 32) can be called 'old information topic'. The left-dislocated NP as an 'aboutness secondary topic' and 'old information topic' is 'identifiable' and expressed through a 'definite NP'15. Identifiablity is the cognitive correlate of definiteness (Lambrecht, 1994: 81) and a definite NP usually contains old information. Some scholars such as Sadeghi (1970) believe that the post position '-ra' can also be counted as 'definite object marker', but sentences like (27) refute the claim:

27) Ketab-i-o, dastan-o ? $\{\mathrm{z}-\{\Sigma \mathrm{t}\{$ ? rif-- $\{\{\mathrm{rd}-\{\mathrm{m}$ ke diruz $\times\{$ rid- $\{\mathrm{m}$.

book-IM ${ }^{16}$-RA story-OM from-PE tell--did-1S which yesterday bought-1S

'As for the book, I told the story from it which I bought yesterday.'

'ketab' (book) in the above example is an indefinite noun phrase and as a noun phrase cannot simultaneously be definite and indefinite, hence, '-ra' (-0) cannot be counted as a definite marker. The referent of this NP is identifiable for the speaker, however, is not identifiable for the hearer and because of this reason is expressed via indefinite NP.

When the left-dislocated NP of a sentence contains new information, that sentence is not acceptable in Persian. In supporting this claim consider the following example:

28) a. Øi d $\{\mathrm{r}-0$ ba $\mathrm{t} \Sigma \mathrm{i}$ baz--k\{rd-i??

you door-OM with what open--did-2S

'What did you open the door with?'

b. ??pit $\Sigma$ gu $\Sigma \mathrm{ti}_{\mathrm{i}}-\mathrm{0}, \varnothing_{\mathrm{j}} \mathrm{d}\left\{\mathrm{r}-\mathrm{o}\right.$ ba- $\Sigma_{\mathrm{i}}$ baz--k $\left\{\mathrm{rd}-\left\{\mathrm{m}_{\mathrm{j}}\right.\right.$

screwdriver-RA I door-OM with-PE open--did-1S

'As for the screwdriver, I opened the door with it.'

Since the sentence initial slot in LDC is reserved for old information and in (28b) the preposed NP (pit $\Sigma$ gu $\Sigma$ ti, 'screwdriver') contains new information which is the answer of the question (28a), this sentence is unacceptable. The leftdislocated constituent as an 'aboutness secondary topic' must be commonly formalized as a definite NP, and its referent must be identifiable, at least, for the speaker (refer to the example 27). As Lambrecht believes the purpose of some constructions is to promote referents on the topic acceptability scale from a non-active to an active state in the discourse (Ibid: 176). Here, as we see, LDC in Persian has such function and promotes a referent to an active state in discourse, and makes it the departure point of message by preposing it to the sentence-initial position as a secondary topic. Therefore, in Persian, LDC is a 'topic-promoting' construction.

Lambrecht believes that 'focus' like 'topic' is a pragmatic relation. Discourse-new referents are commonly presented as a focal constituent. He calls this notion 'focus-newness correlation'. But to him, focus does not always contain new information; rather it may accept some degrees of activation or identifiablity. Thus, focus constituent is not equal to 'new' information, but it is equal to 'non-recoverable' or 'unpredictable' information (Ibid: 222). With this introduction consider the following instance (29):

29) a. pit $\sum$ gu $\Sigma$ tili-o $\varnothing_{j} \mathrm{~d}\{$ r-o ba- $\Sigma$ i baz--k\{rd-ij ja ?\{nbor-d $\{$ sti-0?

screwdriver-RA you door-OM with-PE open--did-2S or pliers-hand-RA

'Did you open the door with a screwdriver or pliers?'

b. pit $\Sigma$ gu $\Sigma$ tili-0, $\varnothing_{j} \mathrm{~d}\left\{\mathrm{r}-0\right.$ ba- $\Sigma_{\mathrm{i}}$ baz--k $\left\{\mathrm{rd}-\left\{\mathrm{m}_{\mathrm{j}}\right.\right.$

screwdriver-RA I door-OM with-PE open--did-1S

'As for the screwdriver, I opened the door with it.'

The NP 'pit $\Sigma g u \Sigma t i$ ' (screwdriver) encompasses the focus domain in (29b) and, however, the topic referent of 'pit $\Sigma$ gu $\Sigma$ ti' is old information (is presented in previous discourse; 29a) but in this proposition has the function of focus. It is focus, because it is unpredictable. This kind of focus is called 'contrastive focus' because it makes the 'pit $\Sigma$ gu $\Sigma \mathrm{ti}$ ' (screwdriver) in contrast to the '? $\{$ nbor-d\{st' (pliers). Contrastive focus usually expresses with a 'contrastive stress'. Hence, another pragmatic function of the preposed constituent in Persian LDC is the function of 'contrastive focus'.

As is clear from (29b), the 'contrastive focus' like the 'aboutness secondary topic' represents with postposition '-ra'. Thus, we can conclude that '-ra' is a functional morpheme which is used for marking 'aboutness secondary topic' and 'contrastive focus' in discourse. Occurring silence or having a short pause after the left-dislocated element which is shown by coma; ',' is another formal marker of LDC which similar to the 'contrastive stress' belongs to the level of phonology.

According to the findings of this research, we can propose a construction for LD in Persian as shown in figure (1):

\footnotetext{
${ }^{15}$ In Persian there is no overt marker for definiteness; only indefiniteness is marked ( Faghiri et al., 2014: 217-237) by indefinite suffix je'.

${ }^{16}$ indefinite marker
} 


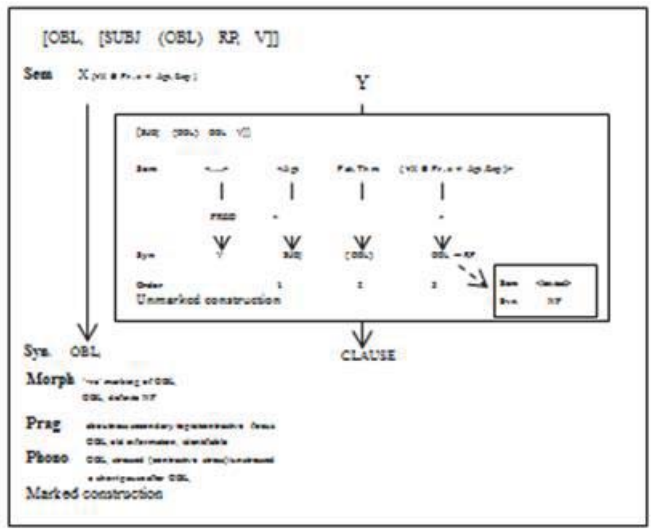

Figure 1. Constructional configuration for Persian left dislocation construction

Figure (1) represents the functional and formal properties of LDC in Persian ${ }^{17}$. The semantic of LDC is directly dependent on the Aktionsart type of the predicate utilized for constructing the sentence. Because of this, its semantics is represented as $\langle\ldots .$. . Figure (1) illustrates that the prepoesd NP (OBL), which is co-indexed with a RP, is marked with postposition 'ra' which, referring to the previous discourse can be the marker of 'contrastive focus' or 'aboutness secondary topic'. This case marking is a surface hallmark of LDC. There occurs also a pause (silence) after the preposed constituent in the phonological representation of LDC. It is a formal marker which is represented at the level of phonology. Left-dislocated NP always contains 'old information' and is 'identifiable' for the addresser. For this reason, it is generally expressed by a definite NP. It can be expressed either with a 'contrastive stress' when is focus, or in 'unstressed' way when is secondary topic. Hence, depending on the two different functions of left-dislocated element, we suggest two constructions for LD IN Persian which can be named 'topic left dislocation construction' and 'focus left dislocation construction'. These two constructions are in polysemy inheritance relationship with each other. It means that they inherit the same syntactic specifications and have a shared set of characteristics. In other words, they only differ in the function of preposed element and the phonetic representation of it -is uttered in a stressed way when is focus and in an unstressed way when is secondary topic. These constructions have their specific formal and functional properties which set them as symbolic units in unique positions in the network of Persian constructions. Their locations in the network are determined by their inheritance relations with other constructions and their degree of motivation.

\subsection{LDC, Inheritance and Motivation}

A syntactic construction can be a combination of various constructions (morphological or syntactic units). In a sentence, different constructions can be combined without any restriction as long as the properties of one do not conflict with the properties of another. Conflicts result in 'ill-formedness' (Goldberg, 2006b).

The grammar of a language, in Goldbergian construction grammar account, is made up of taxonomic networks of constructions, which are shaped based on 'inheritance' and 'motivation'. In defining these two notions in relation to each other is believed that a construction is motivated to the degree that its structure is inherited from other constructions (Goldberg, 1995: 70). In Lakoff's opinion the more motivated construction is, the better it fits into the language system (1987). Constructions are ordered in a hierarchical network. At the top of the hierarchy there are constructions which are inherited by many other constructions. As long as we come to lower levels of the network, less general and rare patterns will present (Goldberg, 2009). This hierarchy is not a strict taxonomy. That is, a construction may inherit properties from multiple constructions above it, in the hierarchy.

17 In the figure RP stands for 'resumptive pronoun', 'Sem' for 'semantics', 'Syn' for 'syntax', 'Morgh' for 'morphology', 'Prag' for 'pragmatics', 'Phono' for 'phonology', 'Pr' for 'participant roles', 'Agt' for 'agent', 'Pat' for 'patient', 'Thm' for 'theme', 'Exp' for 'experiencer', 's for 'or' and 'PRED' for 'predicate'. The arrows indicate that each profiled argument role of the construction fuses with a participant role of the main verb of the sentence; PRED, and then expresses by a syntactic category. The dotted arrow shows the properties of the OBL as a lexical construction. 


\subsubsection{Inheritance}

The manner of inheritance from a construction is a place of conflict. Different models are proposed to explain it (cf. Croft and Cruse, 2004: 277-278). Goldbergian grammar is a 'usage-based model'. Full specification of each construction, in this model, can be avoided by allowing "particular specifications within constructions to have pointers to other information" (Goldberg, 1995: 74), these pointers are called 'inheritance links'. LD can be inherited by many other constructions which we briefly discuss several of them afterwards.

\subsubsection{Ditransitive construction}

There are three different types of ditransitive construction in Persian which are fully depicted in subpart 4.1.3. From these constructions, the 'indirect object construction' (dative construction) and 'dative incorporated construction' can freely inherit LDC; instances of them are shown in (7) and (8b), respectively. But another Persian ditransitive construction; 'object incorporated construction' couldn't be freely in the inheritance relation with LDC. Its inheritance from LDC produces unacceptable and low frequent sentences in Persian as respectively are represented in (9b) and (9c).

\subsubsection{Ezafe construction}

EC as a phrasal construction, in its possessive use ${ }^{18}$, when plays the role of subject as in (30) or oblique of a sentence as in (31) can inherit LDC:

30) h\{msajei, mehmun $-\mathrm{e}-\Sigma_{\mathrm{i}}$ ?um $\left\{\mathrm{d}-\varnothing_{\mathrm{j}}\right.$

neighbor guest-E ${ }^{19}$-PE came-3S

'As for the neighbor, his/her guest came.'(Dabir-Moghaddam, 2006: 52)

31) h\{msaj\{i-ro, ?\{lij der $\left\{x t-e-\Sigma_{i}-0\right.$ xo $\Sigma k$-un-d- $\varnothing_{j}$

neighbor-RA Ali tree-E-PE-OM dry-CC-PAST-3S

'As for the neighbor, Ali dried his/her tree.'

In (30) and (31), the possessor of EC from subject and oblique (direct object) positions have been preposed to the initial position of sentence, respectively. According to the results of the present study, in inheritance from LDC only the oblique can be left-dislocated which is commonly represents with '-ra', and the preposed element plays the role of aboutness secondary topic or contrastive focus. In (30) the preposed NP (h\{msaje) is not the oblique of sentence, is not represented with '-ra' and plays the role of primary topic of sentence, hence, the sentence is not in inheritance relation with LDC. It must be claimed that, in this example just EC and not the sentence are in inheritance relation with LDC. EC as a phrasal construction can partially inherit LDC which is a sentential one. In the inheritance only the modifier of EC moves to the phrase-initial position and a resumptive pronoun remains. Its inheritance is partial because it inherits some (movement and remaining a pronoun) and not all the properties of LDC; eg. the preopsed NP is not represented with '-ra'. The sentence (31), which its oblique is represented in the form of EC, inherits some and not all the properties of LDC. Here, just EC's modifier and not the whole EC as oblique, has been moved to the beginning of sentence. Thus, the sentence inheritance from LDC is defective. The sentence inherits some properties from EC and LDC and also from some canonical constructions such as subject-predicate, transitive and causative constructions.

Double E-construction ${ }^{20}$ (DEC) which is shown in (32a) also can inherit LDC. This construction may inherit LDC in two different ways; one way involves preposing two possessors of DEC as shown in (32b) and the other way is to prepose just the possessor of the embedded EC to the sentence-initial position. You can see an instance of it in (32c). In both of the ways the preposed constituent appears with '-ra'.

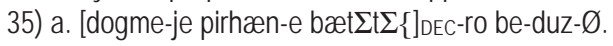

\footnotetext{
${ }^{18}$ Ezafe construction has three Common uses in Persian: 1) Possessive: b\{rad $\{$ re- $M\{r j\{m$ 'Maryam's brother' 2) Adjectivenoun: $b$ \{rad \{r-e-bozorg'the big brother' 3) Given name/title-family name: Moh \{mm \{d-e-Mos \{ddeq 'Mohammad Mosaddegh', aqa-jeMos \{ddeq, 'Mr. Mos \{ddeq' (Moshiri, 1988: 21-23).

19 The Ezafe is a grammatical particle found in some Iranian languages which links two words together; in Persian it consists of the unstressed vowel-e- or -i- (-je- or -ji after vowels) between the words it connects, and often approximately corresponds in usage to the English preposition "of" (Abrahams, 2005: 25). It is realized as an enclitic, links the head noun to its modifiers and to the possessor NP (Samvelian, 2007).

20 Its syntactic structure could be presented in this way: [NPHN-E [NPHN-E NPM]M]
} 


\section{button-E shirt-E kid-OM IMP21-sew.2S}

'Sew the kid's shirt button.'

b. bæt $\Sigma \mathrm{t} \Sigma\{\mathrm{i}-\mathrm{ro}$, pirhænj-e $\Sigma \mathrm{i}-0, \operatorname{dogm}\{-\Sigma j$-o be-duz- $\varnothing$.

kid-RA shirt-PE-RA button-PE-OM IMP-sew.2S

'As for the kid's shirt, sew its button.' (Dabir-Moghaddam, 2006: 239)

c. bæt $\Sigma \mathrm{t} \Sigma\{\mathrm{i}-\mathrm{ro}$, dogme-je pirhæn-e $\Sigma \mathrm{i}-\mathrm{o}$ be-duz- $\varnothing$.

kid-RA button-E shirt-PE-OM IMP-sew.2S

'As for the kid, sew his shirt's button.'

\subsubsection{Complement construction}

A complex sentence construction which contains a clause that functions as a complement of the main verb of a sentence (complement clause) is called complement construction. Meshkato-Dini (2005: 238) states that the advent of a complement clause is a syntactic characteristic of a special group of lexical verbs in Persian which indicate to 'expressive' or 'perceptual' grammatical concepts; the verbs such as 'porsid\{n' (to ask), 'goft\{n' (to say), '?ezhor--k\{rd\{n' (to declare), 'Senid \{n' (to hear), 'danest\{n' (to know), 'fekr--kard\{n' (to think) and 'xast \{n' (to want). In Persian complement construction, the complement clause appears after the linking preposition 'ke' (that). Complement construction can freely inherit LDC in Persian. Consider the example (33):

33) q\{zai-ro, $\Sigma$ ejdaj $\operatorname{motm}\left\{\right.$ ? en-e ke be- $\Sigma_{i} n\left\{m\left\{k--z\left\{d-e-\varnothing_{j}\right.\right.\right.$

food-RA Sheida confident-be that to-PE salt--hit-be-3S

'As for the food, Sheida is confident that she salted it.'

\subsubsection{Relative construction}

A relative construction in Persian may appear in any syntactic position (Dabir-Moghaddam, 2006: 56). It can fully inherit LDC when the preposed element is not coreferential with the subject and the object of the relative clause. Consider the example (34):

34) $m\left\{r_{i}-i-\right.$-ro ke $m\left\{n_{j}\right.$ be- $\Sigma_{i}$ name neve $\Sigma t-\left\{m_{j}, \varnothing_{i} m o ?\{l e m-e\right.$

man-IM ${ }^{22}-\mathrm{RA}$ that I to-PE letter wrot-1S he teacher-is

'As for the man, whom I wrote a letter to him is a teacher.' ((Dabir-Moghaddam, 2006: 57)

Its inheritance from LDC when the left-dislocated element is coreferential with the object of the relative clause is partial; the left-dislocated item, just accepts '-ra' as the aboutness secondary topic or the contrastive focus marker (in accordance with LDC) and leaving nothing in its original position (in contrary with LDC). Preposing an element coreferential with the subject provides an ill-formed sentence. Instances of these two are presented in (35) and (36), respectively:

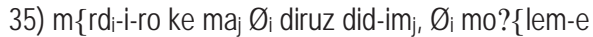
man-IM-RA that we him yesterday saw-1P he teacher-is 'As for the man, whom we saw him yesterday is a teacher.'(Dabir-Moghaddam, 2006)

36) * $m\left\{\right.$ rdi-i-ro ke $\varnothing_{i}$ ba $m\left\{n\right.$ sohb $\left\{t--k\left\{r d-\varnothing_{i}, \varnothing_{i} m o ?\{l e m-e\right.\right.$ man-IM-RA that he with I talk--did-3S he teacher-is 'As for the man, who he talked to me is a teacher.'(Dabir-Moghaddam, 2006)

\subsubsection{Caused-motion construction}

Goldberg (1995) defines this construction structurally in this way: [SUBJ [V OBJ OBL]], where V is a 'nonstative' verb and $\mathrm{OBL}$ is a 'directional phrase'. This definition covers an expression like: They sprayed the paint onto the wall (152). The basic semantics of this construction is that the causer argument directly causes the theme argument to move along a path designated by the directional phrase: that is 'X CAUSES Y to MOVE Z' (Ibid).

Persian caused-motion construction as is instantiated in (37a) can freely inherit LDC and prepose the oblique argument to the sentence-initial position. An example of it is shown in (37b):

\footnotetext{
21 Imperative

22 Indefinite marker
} 
37) a. samani miz-o be $t\left\{r\left\{f-e \quad s\left\{\right.\right.\right.$ ?id hol--dad- $\varnothing_{i}$

Saman table-OM to direction-E Sa'id push--gave-3S

'Saman pushes the table toward Sa'id.'

b. $s\left\{\right.$ ? idi-O, saman ${ }_{j}$ miz-o be $t\left\{r\left\{f-e \Sigma_{\text {i }}\right.\right.$ hol--dad- $\varnothing_{j}$

Sa'id-RA Saman table-OM to direction-PE push--gave-3S

'As for Sa'id, Saman pushes the table toward him.'

In addition to the indicated constructions, there are many other ones which can inherit LDC freely; constructions such as coordinate construction, conditionals, resultative construction and so on, which must be examined in an independent work. According to the findings of this article it has been clarified that LDC is an abstract syntactic construction belonging to the upper levels of hierarchical network of Persian constructions which its structure can be inherited by different less abstract syntactic constructions.

\subsubsection{Motivation}

LDC inherits some properties from other constructions, too. For instance, LDC along with constructions such as TOP and VP-preposing, which prepose a constituent to the left periphery of a sentence, inherits a more abstract construction which can be named 'Left Isolation Construction'. LDC also inherits some canonical constructions such as 'intransitive construction', 'transitive construction, 'passive construction', 'causative construction', 'NP construction', 'VP construction' and some other abstract ones. These constructions are located at upper levels than LDC in the hierarchical network of constructions in the mind of Persian speakers and their properties can be inherited by many other lower constructions such as LDC. As a result, LDC is also a more motivated construction in Persian and can inherit some properties from more abstract constructions.

\section{Conclusion}

It can be concluded that LD as a syntactic two-place construction is responsible for preposing the oblique to the sentence-initial position by leaving a pronominal enclitic coreferential with it in its original place. The preposed NP which its function can be an 'aboutness secondary topic' or 'contrastive focus' is normally marked with the postpostion '-ra'. In this construction, except the agent and the experiencer roles, the other participant roles can be left-dislocated and a verb belonging to any Aktionsart type may be included in it. It has been proved that the Goldbergian construction grammar could provide a comprehensive description of LDC in Persian by revealing its formal and functional properties as a symbolic unit. It also specified its position in the hierarchical network of constructions in the mind of Persian speakers. The construction grammar also revealed that the structure of LDC as an abstract construction can be inherited by some less abstract constructions and also inherits some properties from more abstract ones. Accordingly, the hypotheses of this article were proven by the results.

\section{References}

Abrahams, Simin. (2005). Modern Persian. Routledge.

Allan, K. (1986). Linguistic Meaning. Vol. 1. London and New York: Routledge and Kegan Page.

Allan, K. (2014). Linguistic meaning: Routledge.

Bencini, G. M. L and Adele E. Goldberg. (2000). the Contribution of Argument Structure Constructions to Sentence Meaning. Journal of Memory and Language 43, 640-651.

Croft, W., \& Cruse, D. A. (2004). Cognitive linguistics: Cambridge University Press.

Croft, William (1991). Syntactic categories and grammatical relations. Chicago: University of Chicago Press.

Dabir-Moghaddam M. (1992). On the (in)dependence of syntax and pragmatics: Evidence from the Postposition '-ra' in Persian. in D. Stein (ed.). Cooperating with Written Texts: the Pragmatics and Comprehension of Written Texts. 549-573. Berlin: Mouton de Gruyter.

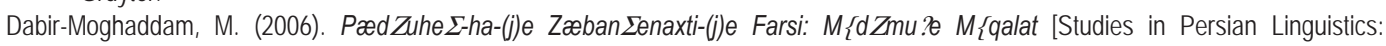
Selected Articles]. Tehran: Iran University Press.

Dixon, R. M., \& Aikhenvald, A. Y. (1997). A typology of argument-determined constructions. Essays on Language Function and Language Type. Dedicated to T. Givón. Benjamins, Amsterdam, 71-113.

Evans, V. and M. Green. (2006). Cognitive linguistics: An introduction. Lawrence Erlbaum Associates Publishers.

Faghiri, P., Samvelian, P., \& Hemforth, B. (2014). Accessibility and Word Order: The Case of Ditransitive Constructions in Persian. Paper presented at the 21st International Conference on Head-Driven Phrase Structure Grammar, University at Buffalo. 
Fillmore, Charles J. (1968) "The Case for Case". In Bach and Harms (Ed.): Universals in Linguistic Theory. New York: Holt, Rinehart, and winston, 1-88.

Givon, T. (1990). Syntax: a functional-typological introduction (Vol. 2). Amsterdam: John Benjamins.

Goldberg, A. E. (1995). Constructions: A construction grammar approach to argument structure. Chicago, IL: Univ. of Chicago Press.

Goldberg, A. E. (2003). Constructions: a new theoretical approach to language. Trends in cognitive sciences 7(5): 219-224.

Goldberg, A. E. ( 2006a). Constructions at work. New York: Oxford University Press.

Goldberg, A. E. (2006b). Constructions at Work: The Nature of Generalization. Language.

Goldberg, A. E. (2009). The nature of generalization in language. Cognitive Linguistics, 20(1), 93-127.

Green, G. (1974). Semantics and syntactic regularity. Bloomington, IN: Indiana Univ. Press.

Gregory, M. L., \& Michaelis, L. A. (2001). Topicalization and left-dislocation: A functional opposition revisited. Journal of pragmatics, 33(11), 1665-1706.

Haspelmath, M. (2008). Ditransitive constructions. Studies in Language Companion Series (SLCS).

Jackendoff, R. (1972). Semantic interpretation in generative grammar. MIT press Cambridge, MA.

Jackendoff, R. (1990). Semantic structures. Cambridge: MIT Press.

Lakoff, G. (1987). Women, fire, and dangerous things: What categories reveal about the mind. Chicago: University of Chicago Press.

Lambrecht, K. (1994). Information structure and sentence form: Topic, focus, and the mental representations of discourse referents. Cambridge: Cambridge university press.

Langacker, R. W. (1987). Foundations of cognitive grammar: Theoretical prerequisites: Stanford University Press.

López, L. (2009). A derivational syntax for information structure (Vol. 23): Oxford University Press.

Mahootian, S., \& Gebhardt, L. (1997). Persian Descriptive grammars: London: Routledge.

Meshkato-Dini, Mehdi. (2005). $D_{\{}$sstur Z \{ban-e Farsi: VoZegan v\{ Peiv\{ndha-je Saxti [Persian Grammar: the Lexical Categories and Merge]. Tehran: SAMT.

Moshiri, Leila. (1988). Colloquial Persian. Routledge.

O'Grady, W., Dobrovolsky, M., \& Aronoff, M. (1997). Contemporary Linguistics. New York: St: Martin's Press.

Perry, J. R. (2005). A Tajik Persian reference grammar (Vol. 11): Brill Academic Pub.

Prince, E. F. (1997). on the functions of left-dislocation in English discourse. Directions in functional linguistics, ed. by Akio Kamio, 117143. Philadelphia: John Benjamins.

Prince, E. F. (1984). Topicalization and Left-Dislocation: A Functional Analysisa. Annals of the New York Academy of Sciences, 433(1), 213-225.

Rahimian, J. (1995). Clause types and other aspects of clause structure in Persian: A study oriented towards comparison with English. Ph.D. Dissertation: The University of Queensland.

Ross, John R. (1967). Constraints on variables in syntax. Ph.D. dissertation: MIT.

Sadeghi, A. A. (1970). 'ra' d\{r farsi-e ?emruz ['ra' in Contemporary Persian]. Journal of Literature and Humanities Department of Tabriz University 93, 9-22.

Saeed, J. I. (2009). Semantics (3 ed.): Blackwell Publishers Ltd.

Samvelian, P. (2007). A (phrasal) affix analysis of the Persian ezafe. Journal of Linguistics 43(3). 605-645.

Sasse, H.-J. (2006). "Aspect and aktionsart". Hand book of linguistics. Elsevier Ltd: pp 535-538.

Shahidi, N. (2000). Mobt\{dasazi $d\{r$ z $\{$ ban-e Farsi ba negahi $n\{q \Sigma g\{$ ra [Topicalization in Persian: a Functional Perspective]. MA Thesis: Allame Tabatabai University, Tehran.

Schiffrin, D., Tannen, D., \& Hamilton, H. E. (2008). The handbook of discourse analysis: John Wiley \& Sons.

Vaezi, H. (2015). Ditransitive Verbs in Persian: Interaction between Syntax and Discourse. Language Related Research, Vol.5, No.5 (Tome 21).

Van Valin Jr, R. D. (2005). Exploring the syntax-semantics interface. New York: Cambridge University Press.

Van Valin Jr, R. D. (2013). Lexical representation, co-composition, and linking syntax and semantics. Advances in generative lexicon theory (pp. 67-107): Springer.

Van Valin, R. D. J. \& R. J. LaPolla. (1997). Syntax: Structure, meaning, and function. New York: Cambridge University Press. 